\title{
Erratum to: Anatomical recommendations for safe botulinum toxin injection into temporalis muscle: a simplified reproducible approach
}

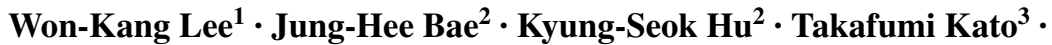 \\ Seong-Taek Kim ${ }^{1,2}$
}

Published online: 13 September 2017

(C) Springer-Verlag France SAS 2017

\section{Erratum to: Surg Radiol Anat (2017) 39:263-269 \\ DOI 10.1007/s00276-016-1739-1}

In the original publication of the article the Figs. 3 and 4 captions has been published incorrectly. the correct captions of Figs. 3 and 4 are as follows:

The online version of the original article can be found under doi:10.1007/s00276-016-1739-1.

\section{Seong-Taek Kim}

k8756050@yuhs.ac

1 Department of Orofacial Pain and Oral Medicine, Yonsei University College of Dentistry, Seoul, South Korea

2 Division in Anatomy and Developmental Biology, Department of Oral Biology, Human Identification Research Center, Yonsei University College of Dentistry, 50 Yonsei-ro, Seodaemun-gu, Seoul 120-749, South Korea

3 Department of Oral Anatomy and Neurobiology, Osaka University Graduate School of Dentistry, Osaka, Japan

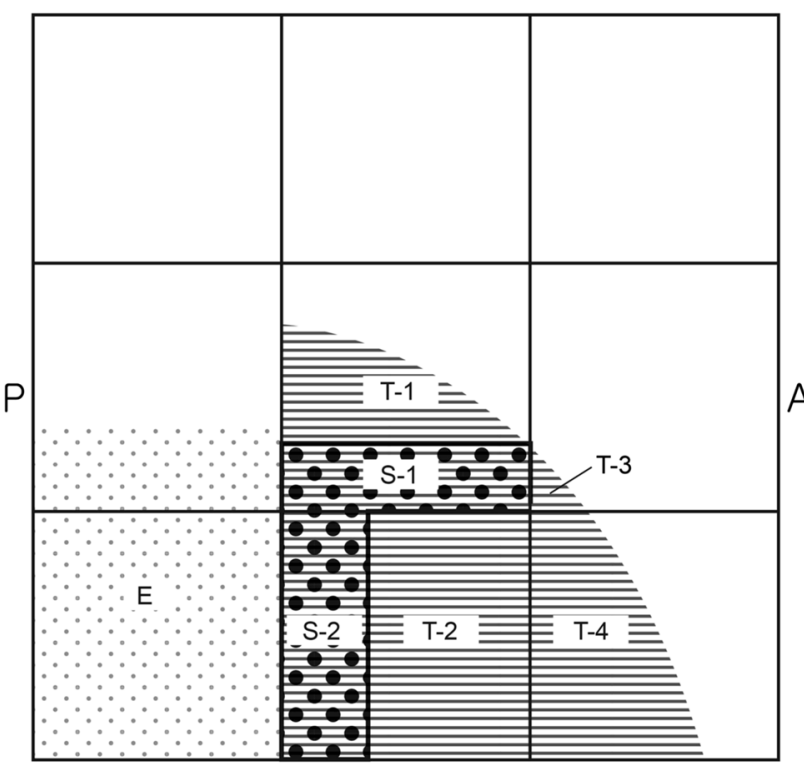

E. External ear : $32.2 \%$

T. Temporalis tendon

T-1. 65\%

T-2. $100 \%$

T-3. $10 \%$

T-4. $53 \%$

S.Superficial temporal artery (STA)

S-1. $30 \%$

S-2. $32 \%$

Fig. 3 The percentages occupied by the main anatomical structures on each compartment. $E$ external ear, $T$ temporalis tendon: T-1. $65 \%$, T-2. $100 \%$, T-3. $10 \%$, T-4. 53\%, $S$ superficial temporal artery: S-1. 30\%, S-2. 32\% 


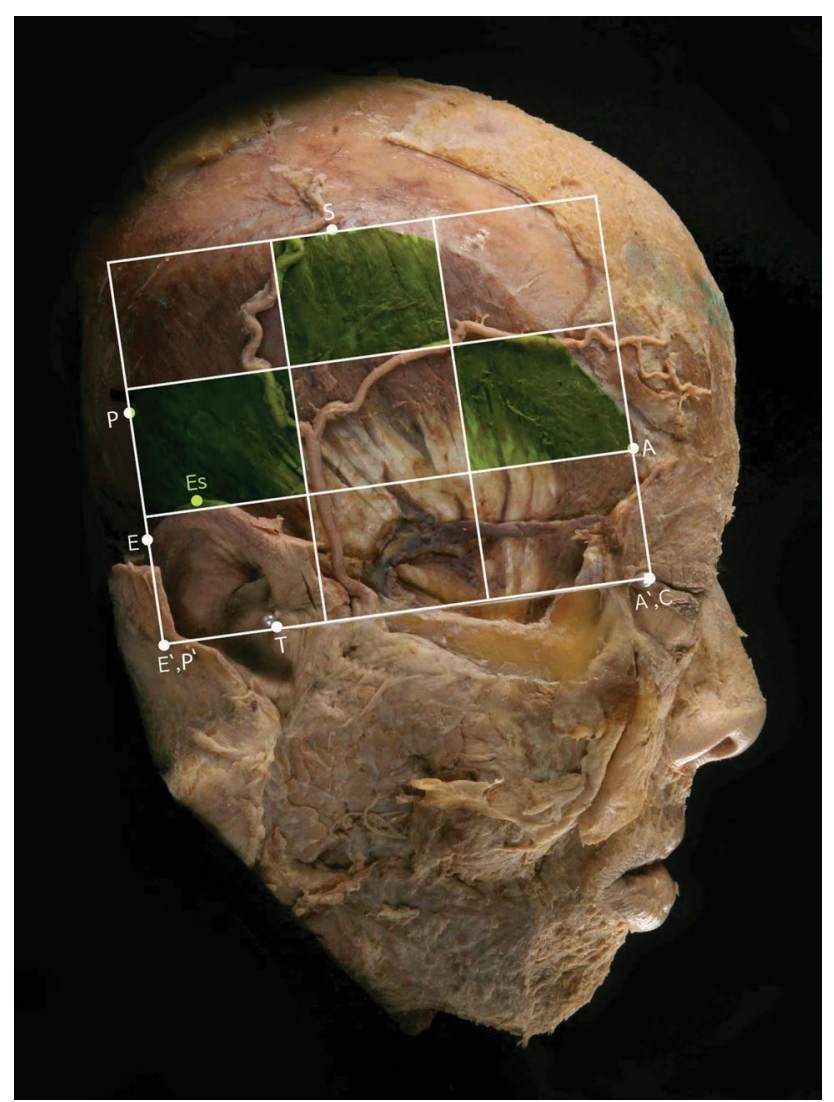

Fig. 4 Recommended injection sites within the nine compartments are shaded in the clinical photo of simplified reproducible approach in a cadaver 